Analysis

\title{
More than total economic value: How to combine economic valuation of biodiversity with ecological resilience
}

\author{
Jeroen F. Admiraal ${ }^{\text {a,* }}$, Ada Wossink ${ }^{\text {b }}$, Wouter T. de Groot ${ }^{\mathrm{a}, \mathrm{c}}$, Geert R. de Snoo ${ }^{\mathrm{a}}$ \\ a Conservation Biology, Institute of Environmental Sciences, Leiden University, P.O. Box 9518, 2300 RA Leiden, The Netherlands \\ b Economics, School of Social Sciences, The University of Manchester, Oxford Road, Manchester, M13 9PL, United Kingdom \\ c ISIS, Faculty of Science, Radboud University Nijmegen, Heijendaalseweg 135, 6525 AJ Nijmegen, The Netherlands
}

\section{A R T I C L E I N F O}

\section{Article history:}

Received 16 July 2012

Received in revised form 14 February 2013

Accepted 16 February 2013

Available online xxxx

\section{Keywords:}

Total economic value

Biodiversity

Ecosystem services

Ecosystem functioning

Functional diversity

Ecosystem resilience

Insurance value

Portfolio theory

\begin{abstract}
A B S T R A C T
The assessment of total economic value has become a pragmatic and popular approach in nature valuation, yet criticisms have been raised. One major point of critique is that total economic value bases the monetary value of ecosystems purely on the flow of human benefits of services of ecosystems and consequently ignores questions of sustainable use of natural capital per se. This paper explains why total economic value by itself is in principle an inadequate concept to guide sustainable use of ecosystems and gives an overview of essential ecological theory that needs to be taken into account in addition to total economic value to fully include ecosystem sustainability. The paper concludes with a framework for combining ecological theory with economic valuation. The key elements here are theoretical ecological insights about ecosystem resilience and portfolio theory which offers an economic perspective on investment in biodiversity. Portfolio theory puts total economic value in a framework where investment in biodiversity is expanded to cover functional diversity and mobile link species in order to maintain ecosystem resilience and so fosters sustainable use of ecosystems.
\end{abstract}

(c) 2013 Elsevier B.V. All rights reserved.

\section{Introduction}

Economic valuation of the services provided by nature is widely perceived by scientists and policy makers as an appealing and important approach to support management decisions (Costanza et al., 1997; Losey and Vaughan, 2006; Nunes and Van den Bergh, 2001; Pimentel et al., 1997). The use of economic values is attractive in that it enables nature to be taken into account in social development, research and policy and promises sustainable use of natural resources, landscape restoration and efforts of conservation. The most inclusive way of economic valuation of nature is through a total economic value assessment. Total economic value is an expression of the total value of the benefits derived from a marginal change in an ecosystem, expressed in monetary terms, which can subsequently be used in cost-benefit models. Total economic value is especially attractive because it aims to cover all expressions of value, including use values and non-use values of ecosystems. For an overview, see Bateman et al. (2011), Dziegielewska (2009) and TEEB (2010).

Yet, during the last decade criticisms have been raised (Bockstael et al., 2000; Chee, 2004; Gatto and De Leo, 2000; Ludwig, 2000; Morse-Jones et al., 2011). Existing economic valuation methods that are used in total economic value calculations, such as production function approaches and contingent valuation methods, refer to the

\footnotetext{
* Corresponding author. Tel.: + 31715275557.

E-mail address: admiraal@cml.leidenuniv.nl (J.F. Admiraal).
}

value of nature to humans, supposedly acting as rational actors (Bockstael et al., 2000; Farber et al., 2002). The aggregate of their individual preferences forms total economic value and supports decisions in ecosystem management. However, if consumer preferences are not in line with the requirements of ecosystem sustainability, total economic value will not express these requirements either (Common and Perrings, 1992). Assuming that ecosystem sustainability would be a preferred status by consumers, one reason why consumer preferences might not be in line with such requirements is an information problem, where the consequences of action and decision on ecosystem sustainability are not well known by consumers (Chee, 2004; Ludwig, 2000). For example, Peterson et al. (2003) describe an ecosystem management model of oligotrophic lakes, which deliver ecosystem services such as water for consumption, irrigation and industrial use, recreation and fish catch. The example shows how a management decision making process that aims to maximize net present value of a lake does not take into account ecosystem resilience, and leads to ecosystem collapse.

There is a necessity to solve this information problem. Ecosystems behave in erratic ways and display time-lagged responses (Holling, 1992; Scheffer and Carpenter, 2003; Scheffer et al., 2001), and because economic valuation of services tracks marginal changes in ecosystem's benefits to humans, the method is blind to erratic behavior of ecosystems. Loss of species and resilience can happen unobserved while ecosystem functioning itself can remain largely unchanged (Chillo et al., 2011; Scheffer et al., 2001; Sundstrom et al., 2012; Walker et al., 
2010). Hence, total economic value by itself cannot give an indication of an ecosystem's ability to maintain future provision of services, as collapse of an ecosystem may be only one marginal change ahead (Fisher et al., 2008). Thus, projects that use economic valuations to inform decisions on how much nature to keep and how much to convert to other uses, fail to safeguard ecosystem functioning for future benefit. Anderies et al. (2006) describe an example from management of an agricultural system in Southeastern Australia in which too much vegetation was cleared to keep the ecosystem resilient against flooding. Decision making based on enhancing economic efficiency and productivity became increasingly reactive and incremental, leading to loss of resilience and a lock-in to an unsustainable management trajectory.

Examples of ecosystem collapse in the literature on ecosystem management suggest that higher levels of caution are required in modifying or removing nature for the purpose of economic efficiency (Anderies et al., 2006; Steneck et al., 2011). A more fundamental criticism comes from Ridder (2008), who argues that more cautious management trajectories are not in line with economic valuation of ecosystem services. This is because total economic value resides mainly in certain functional species or species groups, except for some specific ecosystem services such as scenery and ecotourism. According to this reasoning, only the species needed for generating the ecosystem service of choice are to be maintained or cultivated and non-intervention in an ecosystem only applies to those cases where ecosystem services are provided by species or groups that are rare or very sensitive to human disturbances. Then, why have more species than just those that contribute to human benefits as reflected in total economic value? Steneck et al. (2011) consider the case of lobster monocultures in the Gulf of Maine that are threatened by collapse. Through relying on a few economically valuable species and removal of most apex predators through fishing, the lobster fisheries are on the verge of closure and collapse. Lobster monocultures offer large financial gains, but are vulnerable to perturbations such as rising ocean temperature, causing a decline of more than $70 \%$ in lobster abundance and potential great socio-ecological consequences. Low diversity cultivation has been known to increase the chances of pest outbreaks, disease outbreaks, fire and other expected or unexpected consequences (Hooper et al., 2005; Larsen, 1995; Weitzman, 2000). In addition, strategies in land use that support the maintenance of bundles of ecosystem services are recognized as practices to confront negative environmental impacts, while maintaining economic benefits and ecological resilience (Foley et al., 2005).

As is seen from these examples, economic valuation bases the monetary value of ecosystems only on the output of ecosystems at one point in time and space and not on the state of ecosystems (Morse-Jones et al., 2011) (see Fig. 1.). Hence, a major economic challenge is left unaddressed through the total economic value concept, namely how to manage biological diversity to assure a provision of ecosystem services through wider time and space (Perrings et al., 2009). In other words, how to manage the sustainable use of ecosystems (Farber

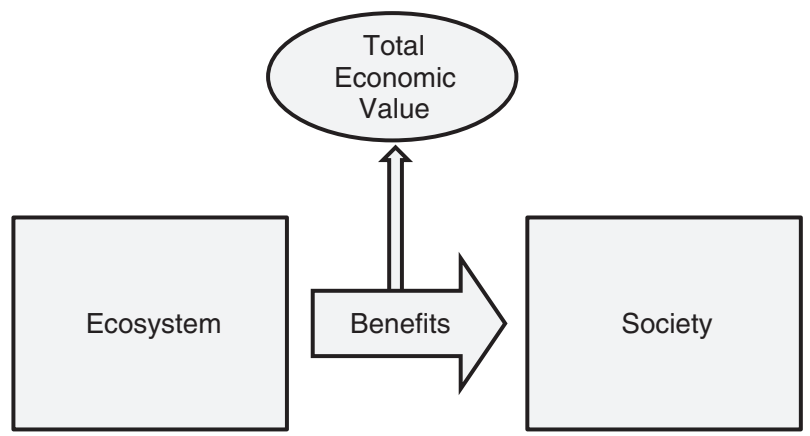

Fig. 1. Total Economic Value represents the value of the output of ecosystems to society, but is no indication of the state of ecosystems. et al., 2002). Using the analogy with factory production, the Millennium Ecosystem Assessment (2005) describes how the flow of goods sold is neither an accurate measure of manufacturing performance nor of the factory's management. The goods could either have been newly produced or taken from an existing built-up stock that is depleting.

In sharp contrast to these characteristics of the total economic value approach, the ecological way of describing the functionality of ecosystems is non-anthropocentric. It describes causal relationships between parts of a system. If ecosystems are seen as assets of humankind, as stocks of natural capital from which ecosystem services flow, ecological "valuations" concern themselves with effects within the stock (Banzhaf and Boyd, 2005). Ecological valuation of ecosystems concerns itself with the maintenance of an ecosystem's complexity, structure, capacity for self-renewal and resilience (Gamborg and Rune, 2004). Ecology may, for example, describe how trees can stabilize slopes or the survival value of certain traits in organisms (Farber et al., 2002). With that, ecological theories are intimately linked to the concept of ecosystem sustainability and therefore have a potential to fill in the information gap in economic valuation, as it offers a perspective on ecosystem functioning that has economic meaning.

These problems cannot be resolved within total economic value theory as it exists today, because the empirical methods used to calculate total economic value are inadequate to address the ecological importance of species functions to sustain ecosystems. This is because, as pointed out by Diamond and Hausman (1994), existing valuation methods suffer from embedding effects in addition to several other limitations. This weakness of economic valuation methods has been recognized, and inclusion of some ecological theory in economic models has become commonplace. The decision on what ecological theory should be included in the economics depends on the spatial scale of the projects considered. Eppink and Van den Bergh (2007) give an overview of the ecological theories already in use in economic models. Some ecological theories tell us something about small-scale dynamics and are therefore useful in small scale cost-effectiveness and resource extraction models. Other theories offer broader system-wide views, and are more useful for economic models that are applied at large spatial scales. Eppink and Van den Bergh conclude that these applications predominantly deal with ecological theory at the species level with a clear absence of ecosystem wide theories of ecosystem resilience. This absence of theory about ecosystem resilience in economic models is problematic.

Inclusion of notions of ecosystem sustainability is essential for sound decision making in ecosystem management. We define ecosystem sustainability in line with the resilience concept (Holling, 1973) as the ecosystem's ability to maintain the provision of ecosystem services into the future. We address the following research questions to explore how the concept of Total Economic Value can be combined with ecosystem sustainability in economic models of nature conservation:

1. What notions of ecosystem resilience need to be added to Total Economic Value assessments in decision making to foster sustainable use of ecosystem services?

2. How can the concept of Total Economic Value be combined with these notions of ecosystem resilience?

The subsequent sections follow this order of research questions. The research questions imply that we maintain an economic and functional outlook on nature. Hence we will not touch on intrinsic values and priorities to protect endangered or characteristic species.

\section{Notions of Ecosystem Resilience to Foster Sustainable Use of Ecosystems}

\subsection{Ecosystem Resilience}

As mentioned above, we define ecosystem sustainability in line with the resilience concept of Holling (1973). More specific, ecosystem resilience according to Holling is the amount of perturbation 
an ecosystem can withstand before relations between organisms (predator and prey, herbivore and resources, or competing species) cause local extinctions and as a consequence cause the ecosystem to shift to another state. Consequently, so-called 'Holling Sustainability' defines an ecosystem as sustainable if it can maintain its self-organization through time by adapting to stresses imposed on it (Common and Perrings, 1992). A second interpretation of ecosystem resilience has been formulated by Pimm (1984) who states that resilience can be defined as the speed with which an ecosystem returns to its former equilibrium state rather than the extent of perturbation it can withstand. The terminology has become more complex ever since (see Loreau et al., 2002) and resilience thinking has expanded to incorporate social-ecological systems (SESs) and the entire Earth System (Folke et al., 2010). In this framework, fostering ecological resilience is seen as a contribution to SES resilience and Earth System resilience. In this paper, we focus exclusively on ecological resilience, for which the definition by Holling remains most in use. Hence, we can refine the information problem in economic valuation to: a lack of information concerning the amount of perturbation an ecosystem can withstand before a shift to another state occurs.

The ecological theory discussed in Sections 2.2 and 2.3 attempts to fill up this lack. There are limits to this exercise, as the precise requirements of ecosystems to maintain their self-organization through time depend on the ecosystem in question and the preferred state of an ecosystem depends on the services desired from it. For example, Carpenter et al. (2001) discuss very practical measures of ecological resilience in an example of lake eutrophication, where the author uses indicators for ecological resilience such as soil P concentration, animal stocking densities, and land area under construction. In the causal chain from human action to an ecosystem adapting to the effects, the indicators such as those used by Carpenter et al. (2001) are the direct causes of perturbations, and not ecosystem adaptability itself. If the physical relations in ecosystems are well understood, such indicators are valid for resilience measurements. However, if such relations are exceedingly complex, ecological theory about ecosystem adaptability still needs to be taken into account and can provide guidelines in maintaining ecosystem resilience. In addition, ecology is limited in its predictive power to describe the sustainable use of any ecosystem service, the relationships between ecosystems and ecosystem services differ per location, and ecological theory can be ill-fitted in the strict framework of stocks and flows with which ecosystem services are regarded and economic valuation relies on (Norgaard, 2010). Therefore, as a necessity the ecological theory presented in this paper is general in outlook.

\subsection{Ecosystem Resilience and Biodiversity}

Work on ecosystem resilience has been expanded with work on regime shifts. If adaptability falls in an ecosystem due to humaninduced disturbances, that ecosystem is more likely to change state, and acquire a new stable state. Regime shifts in ecosystems can cause the loss of valuable ecosystem services and the likelihoods of regime shifts are therefore of concern for sustainable use of ecosystems. Folke et al. (2004) and Scheffer et al. (2001) describe evidence for increased likelihoods of regime shifts in real world ecosystems as groups of species go extinct due to human pressure on ecosystems and give many examples of regime shifts in different biomes. Walker et al. (2004) adds three aspects to ecosystem resilience that describe the local stability of the current state of the ecosystem: latitude, resistance and precariousness (see Fig. 2).

Research on ecosystem resilience has direct implications for biodiversity management. In matters of resilience, biodiversity is seen as protection against loss of productivity or variability of productivity of ecosystems. Experiments with plant species richness confirmed that to ensure the provision of an ecosystem service over time,

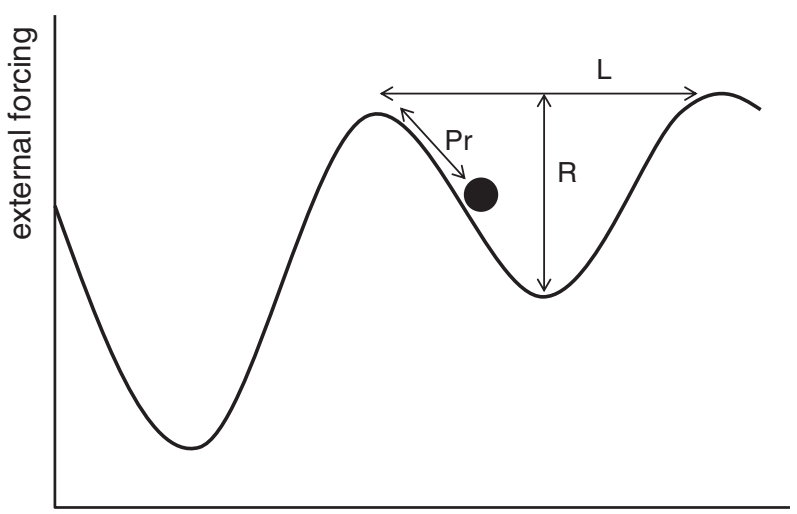

system state

Fig. 2. Ecosystems can switch between states in a stability landscape. A stability landscape is a phase space diagram representing all possible states of an ecosystem. Ecological resilience describes the local stability of the current state of the ecosystem. The black dot represents the state of the ecosystem at a point in time and movement along the hills represents change in the ecosystem. As an ecosystem moves out of a basin, it approaches a threshold, and a regime shift occurs when the ecosystem "falls" into another basin of stability. Resilience has three aspects that describe the ecosystem's location in a stability landscape: latitude, resistance and precariousness. L: latitude, R: resistance, Pr: Precariousness. Adapted from Walker et al. (2004).

greater biodiversity improves ecosystem functioning and the stability of an ecosystem's productivity (Isbell et al., 2011; Tilman et al., 1996). Conversely, if an ecosystem service depends on an ecosystem function that is provided by a single species, the loss of that species will be of greater concern. And loss of biodiversity has a small effect on ecosystem functioning only if no species are lost with singular contributions to ecosystem functioning.

Biodiversity relates to diversity in genes, species and ecosystems, and in the last decade functional diversity has occasionally been added to this list. During this decade, a consensus has been reached among ecologists that the provision of ecosystem services is impacted not so much by species diversity per se in an ecosystem, but by the functional diversity in an ecosystem (Díaz et al., 2006; Peterson et al., 1998). As formulated by McCann (2000), biodiversity by itself is not the driver of ecosystem stability, but ecosystem stability depends on functional diversity capable of differential response to environmental disturbances. Species with different traits react differently towards environmental changes. If species compete for the same resource, decline of one species will lead to an increase of another, which contributes to maintain a stabilization of ecosystem functioning. And in case one species is lost, another will be able to do well under changed conditions, and so contribute to the continuation of the ecosystem as a whole (Vasseur, 2007; Yachi and Loreau, 1999). Thus, the functional diversity in an ecosystem impacts ecological resilience. A greater variety of functional groups in an ecosystem will lead to the presence of more pathways for energy flow and nutrient recycling (Cadotte et al., 2011), which decreases the susceptibility of ecosystems to environmental disturbances and the establishment of invasive species and so leads to a greater ecological resilience (Hobbs et al., 2007; Hooper et al., 2002; Loreau et al., 2002; McCann, 2000; Peterson et al., 1998).

\subsection{Ecosystem Resilience Across Spatial Scales}

Biodiversity is recognized for its role in the preservation of ecological structures at local, regional and global scales. As functional diversity is distributed across scales, ecological resilience is expected to function across scales as well (Peterson et al., 1998). Ecosystems are not closed systems, but are responsive to external input, such as migration of individuals and species dispersal, and are connected through species that serve as "mobile links". Such forces are essential 
to maintain a wide range of functional traits within ecosystems on a local scale (Loreau et al., 2002). On regional and global scales, forces are at play that affect the range of functional traits in ecosystems on local scales. Such forces can be landscape configuration, species dispersal and migration. Through these, local functional traits are maintained in ecosystems, or new functional traits are added to ecosystems. An added complexity is that while regional and global biodiversity supports local ecosystem stability, ecosystems on a local scale in turn support regional and global biodiversity. Ecosystems on a local scale may function as source or sink locations for species populations that range over larger areas. Bird and fish species often feed in one area and breed in another. Forests may provide for the precipitation on agricultural areas. Or one area may provide for the pollination of plant species in another area. Biological control and pollination are ecosystem services especially vulnerable to changes in these forces (Bengtsson et al., 2002). In summary, local, regional and global biodiversity support each other.

The biological linkages between local, regional and global biodiversity are embedded in the concept of "mobile links" (see Fig. 3). Individual animal species can be labeled as mobile links that increase ecological resilience by connecting habitats through genetic exchange, food web linkages or chemical or physical processes (Lundberg and Moberg, 2003). Examples of genetic links are insects that contribute to pollination or seed dispersal in general, and so promote genetic exchange between plants of different areas. Grazers and predators are examples of food web links or trophic links that impact the populations and dispersal of other species. Species with long-distance migrations are seen as links between habitats. In addition to species that fulfill roles as spatial links, there are species that fulfill local resource links, such as scavengers as agents of decomposition, or organisms such as beavers, that function as links in physical processes through dam building. Through mobile links such as seed dispersers, a local loss of species can be replenished from the regional species pool. Thus, regional biodiversity functions as an external ecological memory that enables disturbed local sites to reorganize (Bengtsson et al., 2002; Lundberg and Moberg, 2003). As Loreau et al. (2003) put it, biodiversity on a regional scale provides spatial and temporal insurance against losses in local biodiversity. So while functional diversity supports ecosystem adaptivity, biodiversity on a larger scale supports the functional diversity on smaller scales.

\subsection{In Summary}

This section described notions of ecosystem resilience that need to be added to Total Economic Value assessments to support decisions that foster sustainable use of ecosystem services. An overview was provided of insights from theoretical ecology on ecosystem resilience, the role of functional diversity in ecosystem resilience, and ecosystem resilience across scales through mobile link species. Theory of functional diversity and mobile links can help to inform management on how to support the resilience of ecosystems. Investing in functional diversity and mobile links can improve the adaptability of ecosystems and so prevent ecosystems from undergoing a regime shift to another valley of stability. A recurring theme in these theories is biodiversity as an insurance mechanism. Investing in functional diversity insures an ecosystem against approaching a stability threshold, and investing in biodiversity on a regional scale through supporting mobile link species can be seen as investing in the insurance mechanism of ecological memory, that can replace lost species from a regional species pool.

\section{How can Total Economic Value be Combined with Notions of Ecosystem Resilience?}

In the preceding section, we have expanded on the ecological theory that needs to be incorporated in economic valuation, so that the prescriptions following from it ensure sustainable use of ecosystems. Having first identified the information problem in economic valuation as a lack of information on ecosystem sustainability, and having identified ecosystem resilience, functional diversity and the workings of ecological memory through mobile links as the ecological theory that concerns itself with ecosystem sustainability, we now need to explore how these ecological theories can be combined with economic valuation to establish a new methodology.

\subsection{The Insurance Concept}

A general trend emerges from the ecological theories presented in Section 2, namely that biodiversity acts as an insurance against state change (Baumgärtner, 2007; Swanson, 1992; Yachi and Loreau, 1999). This perspective helps to explain why preserving additional biodiversity

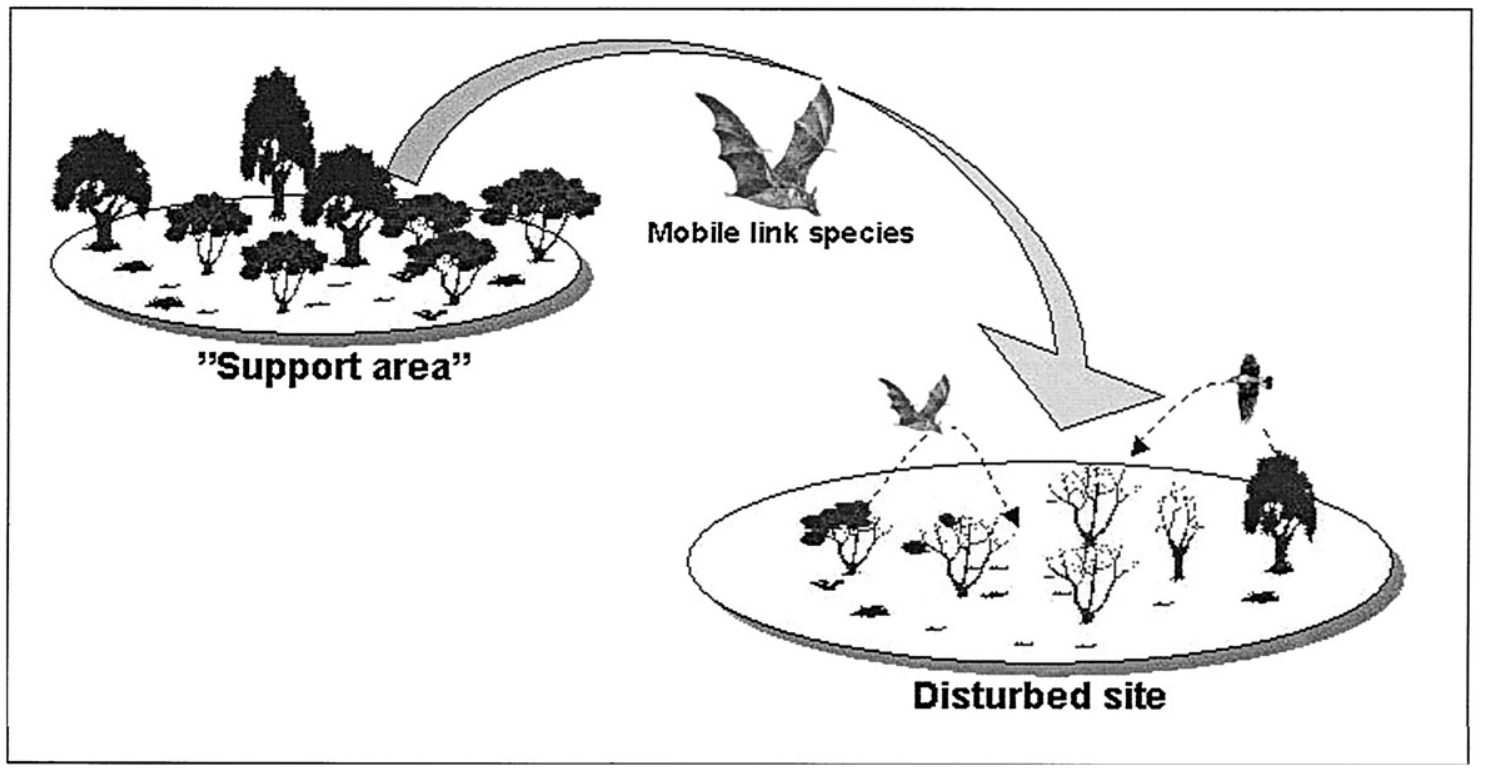

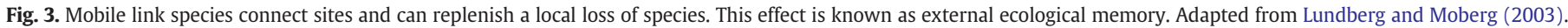


has economic value. In the context of Holling Sustainability, biodiversity (in the manifestations of functional diversity and biodiversity across scales) has a value in insuring human society against loss of ecosystem services through maintaining the adaptability of an ecosystem to biotic and abiotic stresses imposed on it, to prevent it from shifting to another state. Insurance value of biodiversity has also been called the inherent value, contributory value, the indirect value, the primary value or the infrastructure value of biodiversity (Nunes and Van den Bergh, 2001), or has been described as a set of complementary relationships between species in a habitat, between biotic and abiotic components, and functions and services by Fromm (2000).

The insurance value of functional diversity is thought to lie within two parameters: a diversity of functional groups in an ecosystem and the number of species within these functional groups. A diversity of functional groups enables an ecosystem to respond in different ways to disturbances (Cadotte et al., 2011), while having multiple species within functional groups renders the loss of single species less harmful for continued ecosystem functioning. After a local loss of a single species, the species remaining in that same functional group can perform the same function in the ecosystem as the extinct species. Thus, having multiple species within functional groups is regarded as a redundancy of species. Redundancy has negative connotations such as superfluity, but in an ecological sense it is similar to valuable redundancy in software or in the human immune system to boost their reliability (Naeem, 1998; Naeem and Li, 1997). This is also known as the rivet model (Peterson et al., 1998). The insurance value of biodiversity across scales is thought to lie within the mechanism of ecological memory, where the local loss of a species can be replenished from the regional species pool. Such biological exchanges between regional and local biodiversity are facilitated through mobile link species. This insures ecosystems at local scales against functional diversity loss.

Given that the challenge is to maintain ecosystem service provision through time and space, the insurance value of biodiversity shows us that biodiversity (in the manifestations of functional diversity and mobile link species) has an economic value in maintaining ecosystem sustainability, and can (and should) therefore be invested in. Walker et al. (2010) describe the insurance value of biodiversity as a stock of resilience. These authors explain how ecosystem variables characterized by thresholds have a stock of resilience, and how a decline in ecosystem resilience can be considered a decline in wealth. Determining variables with thresholds are for example vegetation connectivity and depth to the water table. If the variable changes, a threshold may be reached that causes the ecosystem to change state. The insurance value of biodiversity refers to such controlling variables, such as "differential response of an ecosystem to disturbances". The stock of resilience is defined as the distance of an ecosystem to the threshold of a state change in a stability landscape, for a particular variable (see Fig. 2). Walker et al. (2010) present an example of including changes in resilience in the estimation of wealth by its quantification for three controlling variables (ground water table, vegetation connectivity and the condition of irrigation infrastructure). To invest in the resilience stock of a variable such as "differential response of an ecosystem", would mean to invest in biodiversity.

We aimed to find an answer to the question: can the concept of total economic value be combined with notions of ecosystem sustainability? We can now further refine that question to: how can we maintain a resilience stock of biodiversity, in combination with the application of traditional economic valuation? A resilience stock of biodiversity would often be comprised of a collection of species populations that would not all be considered needed for optimization of total economic value, because their insurance value is not recognized in total economic value. The benefit to humans, the ecosystem service, of a resilience stock of biodiversity is its capacity to maintain the adaptability of an ecosystem to stresses imposed on it. This capacity is expressed in functional diversity, so insurance value could ideally be expressed as a level of functional diversity, where more diversity equals a greater value.

A problem is that the locations of thresholds in ecosystems are often unknown and that means the size of the resilience stock of an ecosystem is often unknown. Here we run into the limits of ecology's predictive power, and to claim that ecology can predict the precise thresholds and thus the resilience stock in an ecosystem for any ecosystem service would be pretentious (Norgaard, 2010; Polasky et al., 2011). Walters and Maguire (1996) discuss the example of fishery collapses of Atlantic cod. Even in the context of fisheries scientists seeking sustainable harvest regimes, and a decision-making system placing confidence in their scientific models, the collapse of the cod stocks happened unexpectedly, illustrating that ecosystems can change suddenly, and greater caution is required when the location of thresholds in ecosystems are unknown. In ecosystem management, that would translate to making use of working hypotheses that can be revised (Fischer et al., 2009), and a diversification in use of ecological models (Peterson et al., 2003).

Even if quantification of a resilience stock of functional diversity remains out of reach in ecosystem management, investment in a resilience stock of functional diversity is warranted to prevent a regime shift in an ecosystem. Hence, a framework is required in which investment in traditional total economic value can be combined with investment in a resilience stock in such a way that a resilience stock is maintained in the face of optimization of total economic value. To argue for an investment in more biodiversity in order to invest in both total economic value and insurance value is to argue for a diversification in investment, and the economic sense of diversification in investment is explained through portfolio theory. Portfolio theory also allows us to select specific assemblies of biodiversity to take into account in ecosystem management.

\subsection{Portfolio Theory can Combine Total Economic Value with Investment in a Resilience Stock of Biodiversity}

Analogous to financial capital management, sustainable ecosystem management aims to maximize the delivery of ecosystem services while ensuring that the state of ecosystem is maintained. If biodiversity is considered a portfolio of natural assets (Weitzman, 2000) the link with portfolio theory is obvious (e.g., Koellner and Schmitz, 2006; Tilman et al., 1996). More recently this insight has been extended towards its implications for ecosystem management (Figge, 2004). Portfolio theory came about in investment research, because a need for diversification in investment was recognized, but the value of diversification as of yet was still to be described. It was mathematically developed by Markowitz (1952, 1959). In ecosystem services management we observe a similar situation.

Economics has developed a rich literature on how to optimize the use of capital assets. The idea of diversifying one's assets in order to increase return and to manage risk is essential in this literature. Portfolio theory seeks to maximize returns while minimizing risk through the creation of a portfolio of investments that are not positively correlated with one another, thus seeking to assure that the investments held in an account do not all move in a similar pattern. The overall effect of this diversification is to minimize volatility in returns. In ecosystem management, that would translate to building a biodiversity portfolio of genes, species or ecosystems with different characteristics in order to maximize the economic value of ecosystem services, while managing variability or loss of ecosystem services provision (Figge, 2004). The underlying assumption of portfolio theory is that covariance among assets (biodiversity) influences the variance of the returns (services) at any given level of these returns provided by the assets. Portfolio approaches to management compare the tradeoffs between these variances and the level of returns for specific assets. When applied to biodiversity this means that the risk of variability or loss of ecosystem services provided by an ecosystem differs 
depending on the assembly of biodiversity that the ecosystem includes (Figge, 2004).

Examples of the application of portfolio theory in ecosystem management, e.g. Schläpfer et al. (2002) for hay cultivation and Perruso et al. (2005) for fisheries, construct a portfolio of biodiversity to successfully minimize volatility in ecosystem services provision. In these examples, the population assemblies chosen are selected on their ability to minimize volatility of the total economic value of the ecosystem services. We argue that in selecting species populations for a portfolio, the investment should be expanded to include a larger range of species populations comprising both total economic value and insurance value (see Fig. 4). These species populations overlap, as economically valuable species add to the total functional diversity of an ecosystem. Ecological theory predicts that higher levels of biodiversity lead to lower variability in services provision (Isbell et al., 2011; Tilman et al., 1996). More specifically, ecology predicts that small assemblies of species focused on maximizing total economic value risk regime shifts that lead to loss of services, while in larger assemblies of species, a resilience stock is maintained that increases an ecosystem's adaptability to external influences, and thus leads to lower variability of returns. The concepts of functional diversity and resilience across scales add theory on ecological resilience to the portfolio framework, and can guide us to a selection of species whose addition to the portfolio is a priority for keeping ecosystems resilient.

While portfolio theory has so far been presented in the literature as a framework to manage risk, i.e. variability, of ecosystem service provision, we present it as a framework to maintain ecosystem sustainability. Whereas total economic value is a snapshot valuation of ecosystem services, portfolio theory introduces the elements of time and future revenue. Thus the basic idea is that the variance of the total economic value of an ecosystem can be reduced, and service provision kept sustainable, by investing in more functional biodiversity and mobile link species. Theoretically, management alternatives can then be compared based on the expected returns (total economic value) and the risk (variance or loss of the expected total economic value). The quantification of this tradeoff for (a) alternative ecosystems or for (b) alternative plans for one specific ecosystem would provide useful information to support management and species conservation decisions. The trade-offs offer two useful kinds of results in particular. First, for new ecosystem management plans mapping by these two criteria can show which plans are "efficient" in the sense of giving the best expected total economic value performance for a given level of accepted risk, or the least risky outcome at a given total economic value level. Second, trade-off analysis offers an evaluation of existing ecosystems management plans in terms of their relative performance compared to other potential species assemblies.

Portfolio of biodiversity (as proposed in this paper)

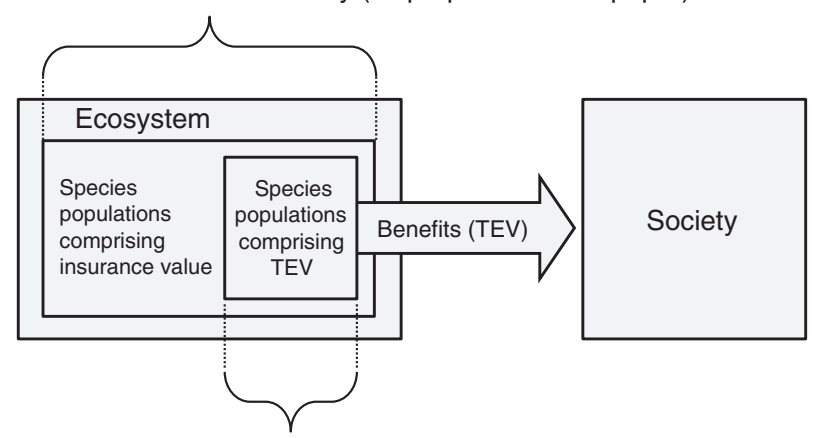

Portfolio of biodiversity (as proposed in extant literature)

Fig. 4. In selecting species populations for a portfolio, investment can be expanded to include a larger range of species populations that comprise both total economic value (TEV) and insurance value. These species populations overlap, as economically valuable species add to the total functional diversity of an ecosystem.
As noted before, the locations of thresholds and thus the level of functional diversity needed to maintain ecosystem sustainability is difficult to assess, yet investment in resilience stocks is warranted. Portfolio theory may not help us to assess the locations of thresholds, but it allows us to set a limit on the functional diversity in danger of being removed from an ecosystem through optimization of total economic value. As a level of sufficient functional diversity is set to prevent the ecosystem undergoing a regime shift, that level of functional diversity is a boundary condition for species assemblies, and limits the number of potential species assemblies under consideration as a portfolio to those that uphold that level of functional diversity. In addition, as a resilient ecosystem is expected to lead to lower variability of returns, the species assembly holding that level of functional diversity also sets the maximum level of accepted risk for other potential species assemblies. Making use of economic valuation in this methodology thus limits the optimization of total economic value by putting a boundary on the minimum level of functional diversity. This way, optimization of total economic value is performed in accordance with a species assembly in a biodiversity portfolio, assessed through guidance by ecological resilience theory that maintains an ecosystem's sustainability.

\section{Conclusion}

The purpose of this paper was to clarify a lack in the concept of total economic value that renders it inadequate to maintain sustainable use of ecosystem services, what notions of ecosystem sustainability can be used to address this lack, and to offer suggestions on how such notions can be combined with total economic value. To do so, the paper has touched upon three different lines of research: (Anderies et al., 2006) research on the limits of optimization of the economic value of ecosystem services, which clarifies the information problem in economic valuation, (Banzhaf and Boyd, 2005) research on ecosystem resilience, which clarifies the characteristics of ecosystems that must be maintained for sustainable use of ecosystem services, from which we concluded functional diversity and mobile link species are its most important characteristics, and (Bateman et al., 2011) research on portfolio theory, which explains the economic sense of extending investment in biodiversity to combat risk of losing returns from ecosystem services.

We expand on earlier research by arguing that these three lines of research can be combined to put total economic value in a framework that would foster sustainable use of ecosystems. The concepts of insurance value and resilience stock are part of resilience thinking, which is a perspective for a sustainability analysis of systems, whereas economic valuation is a method for optimization. This distinction suggests that the two apply to different stages in a process and can therefore complement each other (Fischer et al., 2009). We present portfolio theory as a framework in which investment in total economic value can be combined with investment in ecological resilience. Theory on functional diversity and resilience across scales can provide guidelines for species assemblies that maintain ecological resilience. Such a portfolio of biodiversity will give an investment strategy that most effectively lowers the risk of an ecosystem undergoing a regime shift and thus losing ecosystem services, while in addition allowing for land use strategies of bundles of ecosystem services as opposed to intensification of a single or few ecosystem services. The species assembly invested in sets a limit on future optimization of total economic value, while stabilizing its variance through time and insuring society against its loss. In conclusion, to solve the information problem in total economic value, economic valuation and optimization of an ecosystem's services needs to be performed in accordance with a species assembly in a biodiversity portfolio, assembled through guidance by ecological resilience theory that maintains an ecosystem's sustainability. 


\section{Acknowledgments}

We are grateful to John O'Neill for the discussions and literature suggestions. This research was supported by FP7 Grant Agreement 282625, BIOMOT: MOTivational strength of ecosystem services and alternative ways to express the value of BIOdiversity.

\section{References}

Anderies, J.M., Ryan, P., Walker, B.H., 2006. Loss of resilience, crisis, and institutional change: lessons from an intensive agricultural system in Southeastern Australia. Ecosystems 9, 865-878.

Banzhaf, H.S., Boyd, J., 2005. The architecture and measurement of an ecosystem services index. Sustainability 4, 430-461.

Bateman, I., Mace, G.M., Fezzi, C., Atkinson, G., Turner, K., 2011. Economic analysis for ecosystem service assessments. Environmental and Resource Economics 48 (2), 177-218.

Baumgärtner, S., 2007. The insurance value of biodiversity in the provision of ecosystem services. Natural Resource Modeling 20, 87-127.

Bengtsson, J., Engelhardt, K., Giller, P., Hobbie, S., Lawrence, D., Levine, J., Vila, M., Wolters, V., 2002. Slippin' and slidin' between the scales: the scaling components of biodiversity-ecosystem functioning relations. In: Loreau, M., Naeem, S., Inchausti, P. (Eds.), Biodiversity and Ecosystem Functioning. Synthesis and Perspectives. Oxford University press Inc., New York, pp. 209-220.

Bockstael, N.E., Myrick Freeman III, A., Kopp, R.J., Portney, P.R., Kerry Smith, V., 2000. On measuring economic values for nature. Environmental Science and Technology 34 1384-1389.

Cadotte, M.W., Carscadden, K., Mirotchnick, N., 2011. Beyond species: functional diversity and the maintenance of ecological processes and services. Journal of Applied Ecology 48, 1079-1087.

Carpenter, S., Walker, B., Anderies, J.M., Abel, N., 2001. From metaphor to measurement Resilience of what to what? Ecosystems 4, 765-781.

Chee, Y.E., 2004. An ecological perspective on the valuation of ecosystem services. Biological Conservation 120, 549-565.

Chillo, V., Anand, M., Ojeda, R.A., 2011. Assessing the use of functional diversity as a measure of ecological resilience in arid rangelands. Ecosystems 14, 1168-1177.

Common, M., Perrings, C., 1992. Towards an ecological economics of sustainability. Ecological Economics 6, 7-34.

Costanza, R., dArge, R., deGroot, R., Farber, S., Grasso, M., Hannon, B., Limburg, K., Naeem, S., O'Neill, R.V., Paruelo, J., Raskin, R.G., Sutton, P., vandenBelt, M., 1997. The value of the world's ecosystem services and natural capital. Nature 387, 253-260.

Diamond, P.A., Hausman, J.A., 1994. Contingent valuation: is some number better than no number? The Journal of Economic Perspectives 8, 45-64

Díaz, S., Fargione, J., Chapin III, F.S., Tilman, D., 2006. Biodiversity loss threatens human well-being. PLoS Biology 4 (8), e277. http://dx.doi.org/10.1371/journal.pbio.0040277.

Dziegielewska, D., 2009. Total economic value. In: Tietenberg, T., Niggol Seo, S. (Eds.), Encyclopedia of Earth. Environmental Information Coalition, National Council for Science and the Environment, Washington, D.C. (Available from http://www.eoearth.org/article/ Total_economic_value (accessed June 2012)).

Eppink, F.V., Van den Bergh, J.C.J.M., 2007. Ecological theories and indicators in economic models of biodiversity loss and conservation: a critical review. Ecologica Economics 61, 284-293.

Farber, S.C., Costanza, R., Wilson, M.A., 2002. Economic and ecological concepts for valuing ecosystem services. Ecological Economics 41, 375-392.

Figge, F., 2004. Bio-folio: applying portfolio theory to biodiversity. Biodiversity and Conservation 13, 827-849.

Fischer, J., Peterson, G.D., Gardner, T.A., Gordon, L.J., Fazey, I., Elmqvist, T., Felton, A., Folke, C., Dovers, S., 2009. Integrating resilience thinking and optimisation for conservation. Trends in Ecology \& Evolution 24, 549-554.

Fisher, B., Turner, K., Zylstra, M., Brouwer, R., De Groot, R., Farber, S., Ferraro, P., Green, R., Hadley, D., Harlow, J., Jefferiss, P., Kirkby, C., Morling, P., Mowatt, S., Naidoo, R. Paavola, J., Strassburg, B., Yu, D., Balmford, A., 2008. Ecosystem services and economic theory: integration for policy-relevant research. Ecological Applications 18, 2050-2067.

Foley, J.A., DeFries, R., Asner, G.P., Barford, C., Bonan, G., Carpenter, S.R., Stuart Chapin, F., Coe, M.T., Daily, G.C., Gibbs, H.K., Helkowski, J.H., Holloway, T., Howard, E.A., Kucharik, C.J., Monfreda, C., Patz, J.A., Colin Prentice, I., Ramankutty, N., Snyder, P.K., 2005. Global Consequences of Land Use. Science 309, 570-574.

Folke, C., Carpenter, S., Walker, B., Scheffer, M., Elmqvist, T., Gunderson, L., Holling, C.S. 2004. Regime shifts, resilience, and biodiversity in ecosystem management. Annua Review of Ecology, Evolution, and Systematics 35, 557-581.

Folke, C., Carpenter, S.R., Walker, B.H., Scheffer, M., Chapin III, F.S., Rockström, J., 2010. Resilience thinking: integrating resilience, adaptability and transformability. Ecology and Society 15 (4), 20 (http://www.ecologyandsociety.org/vol15/iss4/art20/).

Fromm, O., 2000. Ecological structure and functions of biodiversity as elements of its total economic value. Environmental and Resource Economics 16, 303-328.

Gamborg, C., Rune, F., 2004. Economic and ecological approaches to assessing forest value in managed forests: ethical perspectives. Society and Natural Resources 17 , 799-815.

Gatto, M., De Leo, G.A., 2000. Pricing biodiversity and ecosystem services: the never-ending story. Bioscience 4, 347-355.

Hobbs, R.J., Yates, S., Mooney, H.A., 2007. Long-term data reveal complex dynamics in grassland in relation to climate and disturbance. Ecological Monographs 77, 545-568.

Holling, C.S., 1973. Resilience and stability of ecological systems. Annual Review of Ecology and Systematics 4, 1-23.
Holling, C.S., 1992. Cross-scale morphology, geometry, and dynamics of ecosystems. Ecological Monographs 62, 447-502.

Hooper, D.U., Solan, M., Symstad, A., Díaz, S., Gessner, M.O., Buchmann, N., Degrange, V., Grime, P., Hulot, F., Mermillod-Blondin, F., Roy, J., Spehn, E., Peer, L., 2002. Species diversity, functional diversity, and ecosystem functioning. In: Loreau, M., Naeem, S., Inchausti, P. (Eds.), Biodiversity and Ecosystem Functioning. Synthesis and Perspectives. Oxford University press Inc., New York, pp. 195-208.

Hooper, D.U., Chapin III, F.S., Ewel, J.J., Hector, A., Inchausti, P., Lavorel, S., Lawton, J.H., Lodge, D.M., Loreau, M., Naeem, S., Schmid, B., Setala, H., Symstad, A.J., Vandermeer, J., Wardle, D.A., 2005. Effects of biodiversity on ecosystem functioning: a consensus of current knowledge. Ecological Monographs 75 (I), 3-35.

Isbell, F., Calcagno, V., Hector, A., Connolly, J., Stanley Harpole, W., Reich, P.B., SchererLorenzen, M., Schmid, B., Tilman, D., Van Ruijven, J., Weigelt, A., Wilsey, B.J., Zavaleta, E., Loreau, M., 2011. High plant diversity is needed to maintain ecosystem services. Nature 477, 199-202.

Koellner, T., Schmitz, O.J., 2006. Biodiversity, ecosystem function, and investment risk. BioScience 56, 977-985

Larsen, J.B., 1995. Ecological stability of forest and sustainable silviculture. Forest Ecology and Management 73, 85-96.

Loreau, M., Downing, A., Emmerson, M., Gonzalez, A., Hughes, J., Inchausti, P., Joshi, J., Norberg, J., Sala, O., 2002. A new look at the relationship between diversity and stability. In: Loreau, M., Naeem, S., Inchausti, P. (Eds.), Biodiversity and Ecosystem Functioning. Synthesis and Perspectives. Oxford University press Inc., New York, pp. 79-91.

Loreau, M., Mouquet, N., Gonzalez, A., 2003. Biodiversity as spatial insurance in heterogeneous landscapes. PNAS 100 (22), 12765-12770.

Losey, J.E., Vaughan, M., 2006. The economic value of ecological services provided by insects. Bioscience 56, 311-323.

Ludwig, D., 2000. Limitations of economic valuation of ecosystems. Ecosystems 3, 31-35. Lundberg, J., Moberg, F., 2003. Mobile link organisms and ecosystem functioning: implications for ecosystem resilience and management. Ecosystems 6, 87-98.

Markowitz, H., 1952. Portfolio selection. Journal of Finance 7, 77-91.

Markowitz, H., 1959. Portfolio Selection: Efficient Diversification of Investments. John Wiley \& Sons, New York.

McCann, K.S., 2000. The diversity-stability debate. Nature 405, 228-233.

Millennium Ecosystem Assessment, 2005. Millennium ecosystem assessment. Island Press, Washington, D.C., USA.

Morse-Jones, S., Luisetti, T., Turner, R.K., Fisher, B., 2011. Ecosystem valuation: some principles and a partial application. Environmetrics 22, 675-685.

Naeem, S., 1998. Species redundancy and ecosystem reliability. Conservation Biology $12,39-45$.

Naeem, S., Li, S., 1997. Biodiversity enhances ecosystem reliability. Nature 390, 507-509.

Norgaard, R.B., 2010. From eye-opening metaphor to complexity blinder. Ecological Economics 69, 1219-1227.

Nunes, P.A.L.D., Van den Bergh, J.C.J.M., 2001. Economic valuation of biodiversity: sense or nonsense? Ecological Economics 39, 203-222.

Perrings, C., Baumgärtner, C.S., Brock, W.A., Chopra, K., Conte, M., Costello, C., Duraiappah, A., Kinzig, A.P., Pascual, U., Polasky, S., Tsschirhart, J., Xepapadeas, A., 2009. The Economics of Biodiversity and Ecosystem Services. In: Naeem, S., Bunker, D., Hector, A., Loreau, M., Perrings, C. (Eds.), Biodiversity, Ecosystem Functioning, and Human Wellbeing: An Ecological and Economic Perspective. Oxford University Press., New York, Oxford, pp. 230-247.

Perruso, L., Weldon, R.N., Larkin, S.L., 2005. Predicting optimal targeting strategies in multispecies fisheries: a portfolio approach. Marine Resource Economics 20, 25-45.

Peterson, G., Allen, G.R., Holling, C.S., 1998. Ecological resilience, biodiversity, and scale. Ecosystems 1, 6-18.

Peterson, G.D., Carpenter, S.R., Brock, W.A., 2003. Uncertainty and the management of multistate ecosystems: an apparently rational route to collapse. Ecology 84, 1403-1411.

Pimentel, D., Wilson, C., McCullum, C., Huang, R., Dwen, P., Flack, J., Tran, Q., Saltman, T., Cliff, B., 1997. Economic and environmental benefits of biodiversity. Bioscience 47. 747-757.

Pimm, S.L., 1984. The complexity and stability of ecosystems. Nature 307, 321-326.

Polasky, S., Carpenter, S.R., Folke, C., Keller, B., 2011. Decision-making under great uncertainty: environmental management in an era of global change. Trends in Ecology and Evolution 26, 398-404.

Ridder, B., 2008. Questioning the ecosystem services argument of biodiversity conservation. Biodiversity and Conservation 17, 781-790.

Scheffer, M., Carpenter, S.R., 2003. Catastrophic regime shifts in ecosystems: linking theory to observation. Trends in Ecology and Evolution 18, 648-656.

Scheffer, M., Carpenter, S., Foley, J.A., Folke, C., Walker, B., 2001. Catastrophic shifts in ecosystems. Nature 413, 591-596.

Schläpfer, F., Tucker, M., Seidl, I., 2002. Returns from hay cultivation in fertilized low diversity and non-fertilized high diversity grassland. Environmental and Resource Economics 21, 89-100.

Steneck, R.S., Hughes, T.P., Cinner, J.E., Adger, W.N., Arnold, S.N., Berkes, F., Boudreau, S.A., Brown, K., Folke, C., Gunderson, L., Olsson, P., Scheffer, M., Stephenson, E., Walker, B., Wilson, J., Worm, B., 2011. Creation of a gilded trap by the high economic value of the Maine lobster fishery. Conservation Biology 25, 904-912.

Sundstrom, S.M., Allen, C.G., Barichievy, C., 2012. Species, functional groups, and thresholds in ecological resilience. Conservation Biology 26, 305-314.

Swanson, T.M., 1992. Economics of a biodiversity convention. Ambio 21, 250-257.

TEEB, 2010. The Economics of Ecosystems and Biodiversity: Mainstreaming the Economics of Nature: A Synthesis of the Approach, Conclusions and Recommendations of TEEB.

Tilman, D., Wedin, D., Knops, J., 1996. Productivity and sustainability influenced by biodiversity in grasslands ecosystems. Nature 379, 718-720. 
Vasseur, D.A., 2007. Spectral Analysis Unmasks Synchronous and Compensatory Dynamics in Plankton Communities. Ecology 88, 2058-2071.

Walker, B., Holling, C.S., Carpenter, S.R., Kinzig, A., 2004. Resilience, Adaptability and Transformability in Social-Ecological Systems. Ecology and Society 9 (2), 5 ([online] URL: http://www.ecologyandsociety.org/vol9/iss2/art5).

Walker, B.H., Pearson, L., Harris, M., Mäler, K.G., Chuan-Zhong, L., Biggs, R., Baynes, T., 2010. Incorporating resilience in the assessment of Inclusive Wealth: an example from South East Australia. Environmental and Resource Economics 45, 183-202.
Walters, C., Maguire, J., 1996. Lessons for stock assessment from the northern cod collapse. Reviews in Fish Biology and Fisheries 6, 125-137.

Weitzman, M.L., 2000. Economic profitability versus ecological entropy. Quarterly Journal of Economics 115, 237-263.

Yachi, S., Loreau, M., 1999. Biodiversity and Ecosystem Productivity in a Fluctuating Environment: The Insurance Hypothesis. Proceedings of the National Academy of Sciences of the United States of America 96, 1463-1468. 